\title{
Rancangan Kontrol AC dan Lampu Kelas dengan Komputerisasi dari Jarak Jauh Berbasis Mikrokontroller
}

\author{
Kustori $^{1}$, Basuki Rokhmat ${ }^{2}$ \\ 1,2)Politeknik Penerbangan Surabaya \\ J1. Jemur Andayani I, No. 73 Surabaya 60236 \\ Email : kustoriatkp@gmail.com
}

\begin{abstract}
ABSTRAK
Sistem pengendalian ac dan lampu merupakan penelitian desain data yang diperoleh dari hasil pengujian rancangan berdasarkan pengukuran dan pengamatan. Tujuan penelitian ini adalah untuk mengontrol ac dan lampu kelas secara jarak jauh. Sistem pengontrolan jarak jauh ac dan lampu pada kelas di Politeknik Penerbangan Surabaya merupakan sebuah perubahan dari sistem sebelumnya yaitu secara manual. Serta terobosan sangat efektif untuk penghematan energi yang mana energi takkan terbuang percuma pada beban yang besar. Karena sistem ini juga dilengkapi dengan sistem sleep (waktu untuk hidup dan mati secara otomatis dapat kita atur).
\end{abstract}

Kata Kunci: Sistem Pengendali, mikrokontroler, otomatis.

\section{PENDAHULUAN}

Politeknik Penerbangan Surabaya adalah lembaga pendidikan yang berada di bawah naungan Badan Pendidikan dan Pelatihan Perhubungan, yang bertujuan untuk menyiapkan peserta didik menjadi anggota masyarakat penerbangan yang memiliki kemampuan profesional serta handal di bidang teknik dan keselamatan penerbangan.

Poltekbang Surabaya memiliki peran yang sangat besar dalam melahirkan masyarakat penerbangan yang handal dan professional sehingga diadakanlah perkembanganperkembangan yang dilakukan Poltekbang Surabaya dalam penyelenggaraan pendidikan. Seperti penambahan fasilitas belajar mengajar, pembangunan, pengadaan peralatan dan penambahan fasilitas-fasilitas yang lain, dimana fasilitas tersebut untuk menunjang agar para taruna dapat menjadi masyarakat penerbangan yang handal dan professional.

Dalam fasilitas-fasilitas tersebut dianataranya adalah pemasangan AC di dalam kelas dimana untuk kenyamanan belajar mengajar agar para taruna dapat dengan optimal mendapatkan ilmu yang diajarkan. Namun pada kenyataannya sekarang ini, dimana para taruna selalu lalai dalam mematikan AC atau lampu sehingga hal ini dirasakan sangat merugikan bagi Poltekbang Surabaya maupun negara, karena dinilai sangat boros dalam hal energi listrik.

Untuk mengatasi masalah tersebut, dibuatlah peralatan yang dapat mengontrol sebuah alat dari jarak jauh dan dimana saja, agar terwujudnya efesiensi dalam penggunaan AC dan lampu dalam kelas.

\section{METODE PENELITIAN}

\section{Kondisi Saat Ini}

AC dan lampu dalam kelas tidak memiliki kontrol jarak jauh yang hanya bisa di kontrol di dalam kelas, padahal masih banyak para taruna yang tidak mematikan AC dan lampu kelas setelah kegiatan perkuliahan. Hal ini mengakibatkan pemborosan energi padahal kita ketahui sendiri bahwa sumber daya untuk energi listrik terbatas. 


\section{Kondisi yang Diinginkan}

Dalam menegakkan kedisiplinan dalam kelas di Politeknik Penerbangan Surabaya adalah terciptanya sebuah alat pengontrol AC dan lampu jarak jauh yang mana dapat diatur mati hidupnya secara otomatis dari jarak jauh tanpa harus datang ke kelas. Kontrol digunakan agar kita dapat menekan pemborosan energi namun harus ada operator yang dapat memantau dan mengontrolnya walaupun operator tidak berada ditempat (jarak jauh).
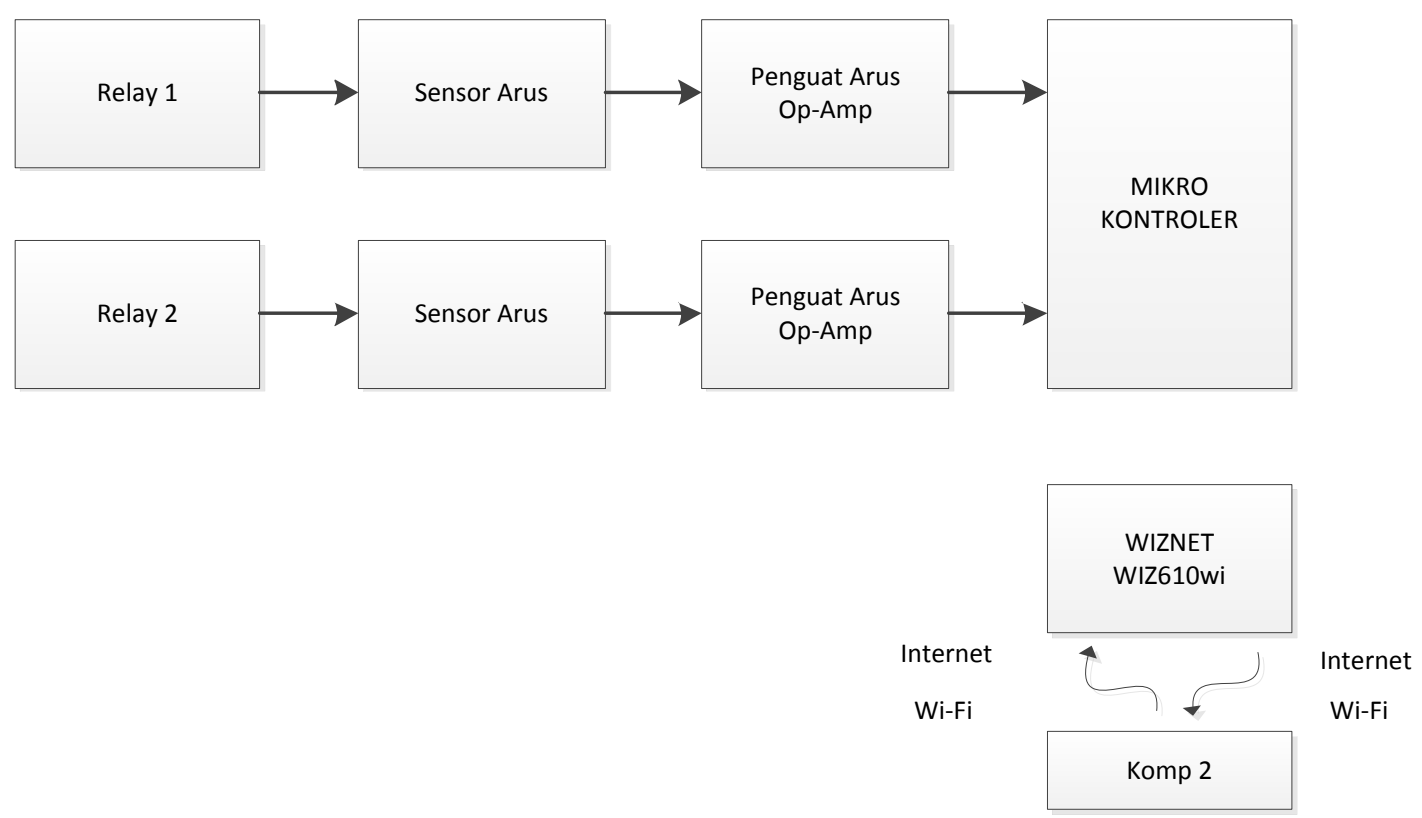

\section{Gambar 1. Blok Diagram Rancangan}

Mikrokontroler digunakan sebagai pengolah data dari sensor arus yang kemudian data tersebut dikirimkan ke Wiznet tipe WIZ610wi, yang kemudian oleh Wiznet tersebut dikirimkan kembali ke sebuah komputer dan mikrokontroller yang juga berfungsi sebagai pengeksekusi setelah mendapat perintah dari komputer. WIZNET tipe WIZ610w adalah modul gerbang yang mana menyediakan sebuah hubungan untuk Ethernet yang dapat menghasilkan jaringan wireless yang mana digunakan sebagai hubungan anatara mikrokontroller dengan komputer. Komputer berfungsi sebagai server dimana disini tempat untuk client member perintah kepada mikrokontroller untuk mengekskusi perintah dari client. 


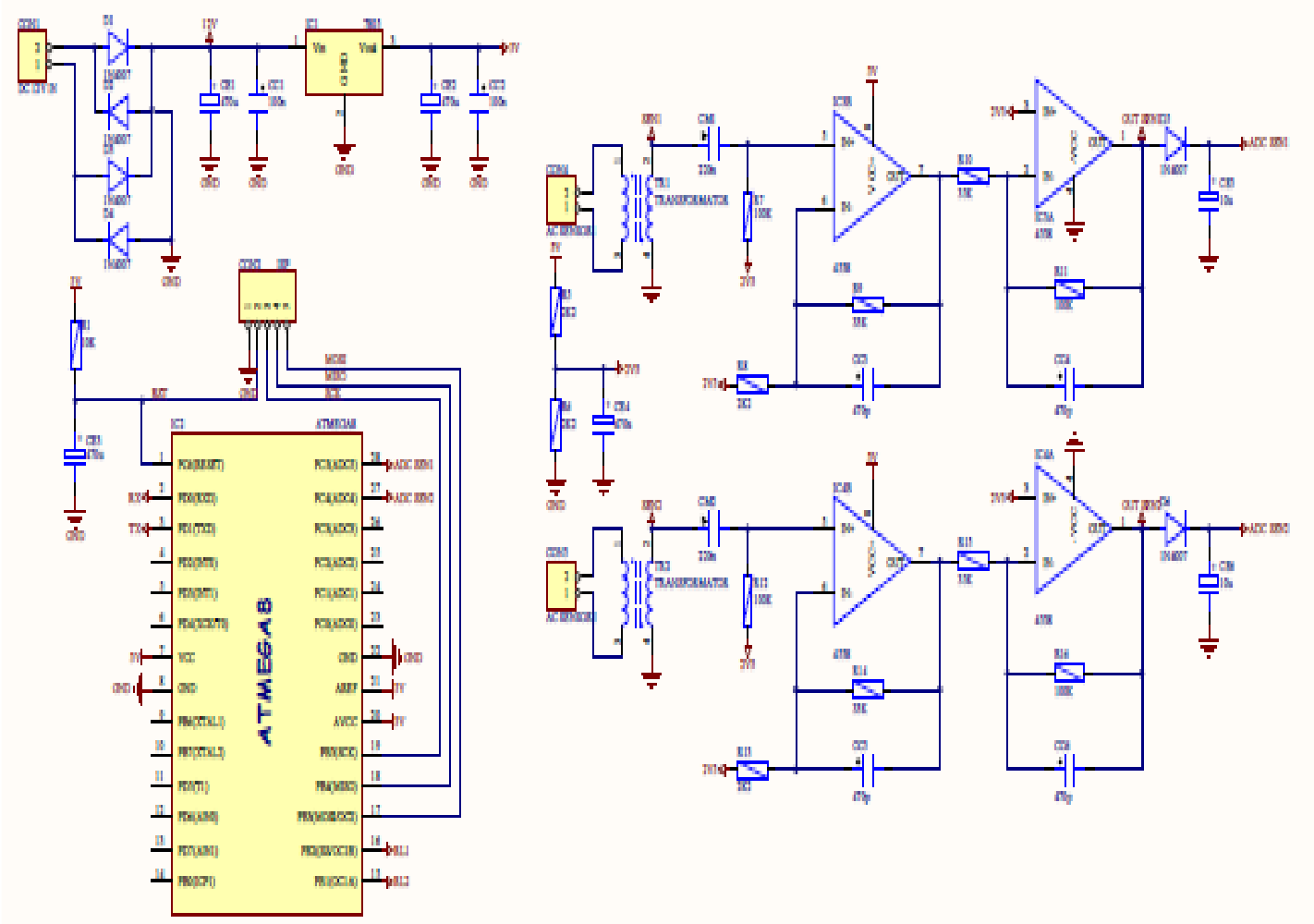

Gambar 2. Rangkaian Kontrol AC dan lampu

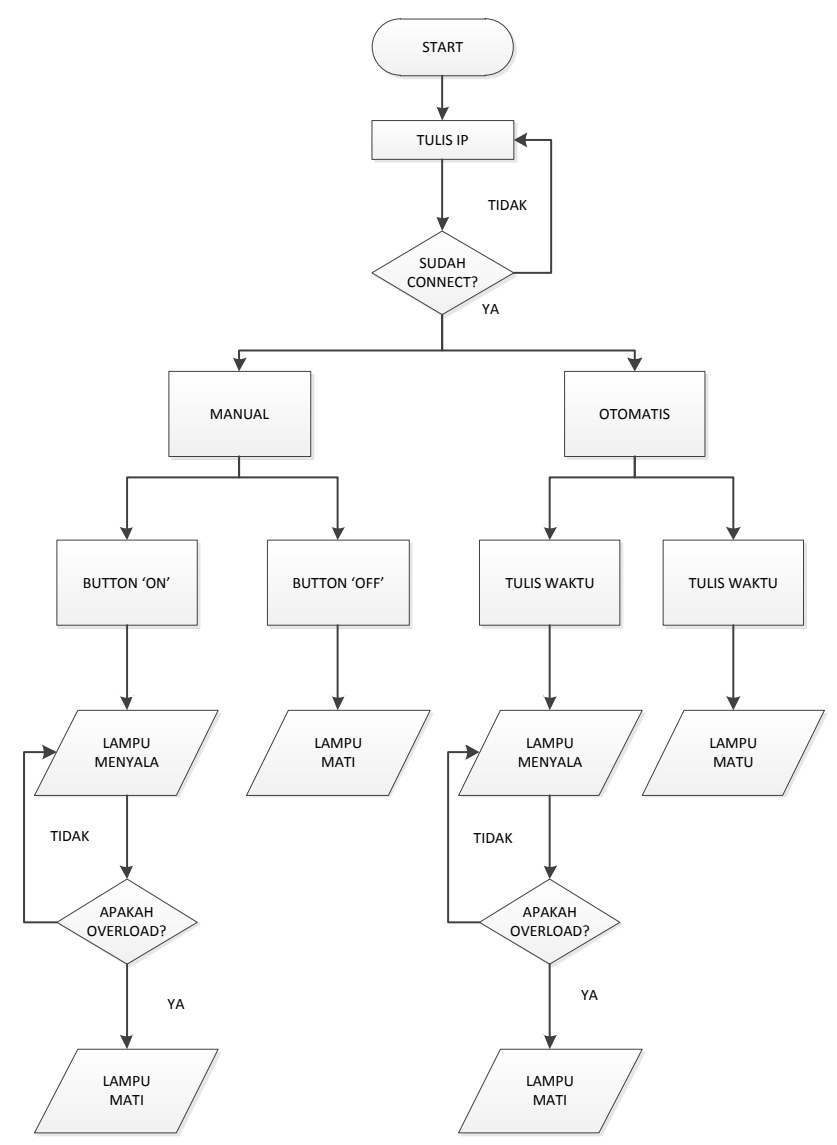

Gambar 3. Diagram Alir 


\section{HASIL PENELITIAN}

\section{Analisa Data yang Diterima Mikrokontroller}

Analisa data berikut berisikan tentang nilai arus yang masuk pada Rx dari mikro dan ini berdasarkan jumlah besar daya yang digunakan pada beban.

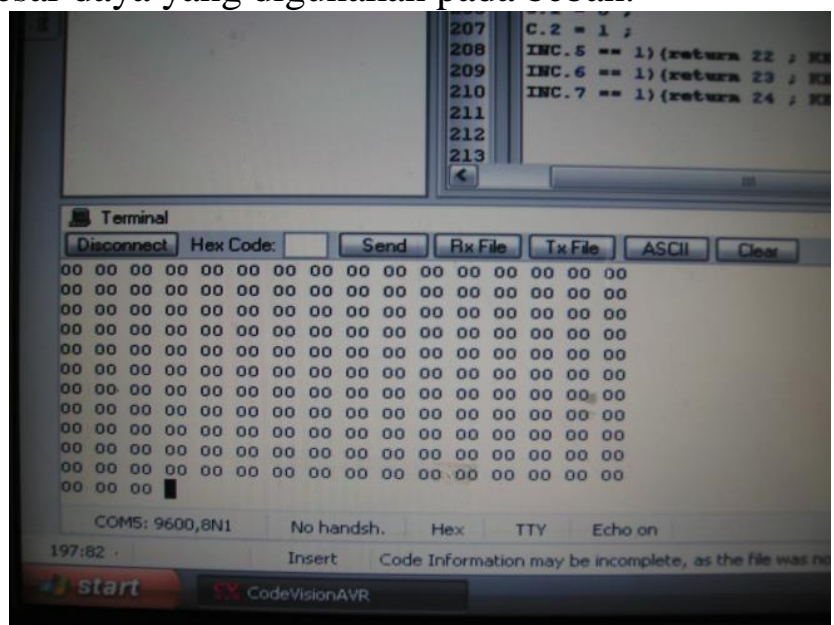

Gambar 4. Analisa Arus yang Masuk Pada Mikrokontroller Tanpa Beban

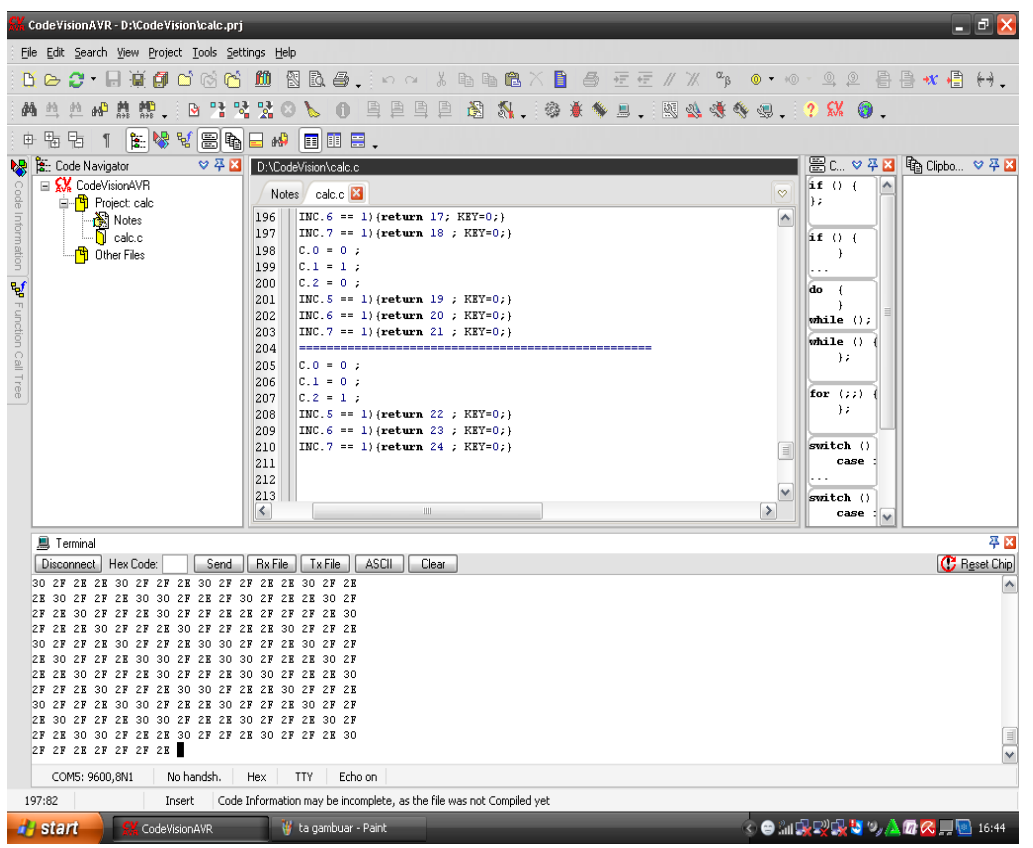

Gambar 5. Analisa Arus yang Masuk Pada Mikrokontroller Dengan Beban 


\section{Analisa Data yang Diterima Oleh Delphi}

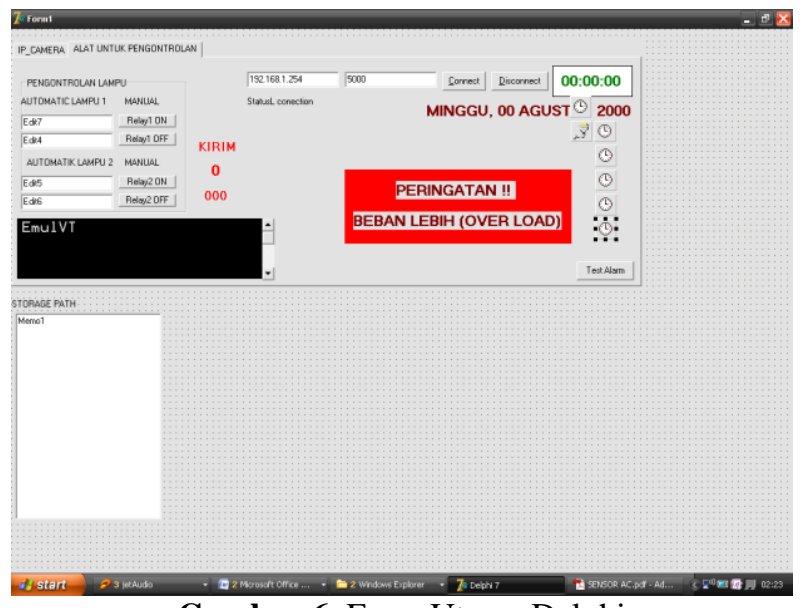

Gambar 6. Form Utama Delphi

Untuk bagian koneksi, terdiri dari pengisian IP dan Port yang nantinya akan dihubungkan dengan wireless yang dipancarkan modul WIZNET WIZ610wi. Untuk bagian kontrol terdapat dua bagian yaitu bagian Manual dan bagian Otomatis. Untuk bagian Manual terdiri dari dua tombol ON dan OFF. Jika menekan tombol ON maka lampu akan menyala, dan jika menekan tombol OFF maka lampu akan mati. Namun, apabila ketika menyalakan lampu sedangkan lampu yang dibebankan ternyata overload maka akan muncul peringatan bahwa beban overload pada form. Dan secara otomatis lampu akan mati.

Untuk bagian Otomatis terdiri dari pengisian waktu untuk ON dan OFF. Jika dimasukkan waktu pada kotak ON, maka lampu akan menyala sesuai dengan waktu yang ditetapkan. Begitu juga dengan ketika mengisi waktu pada kotak 'OFF', maka lampu akan mati sesuai dengan waktu yang ditetapkan. Pada bagian Otomatis ini juga diberikan peringatan apabila beban overload yang akan langsung mematikan lampu.

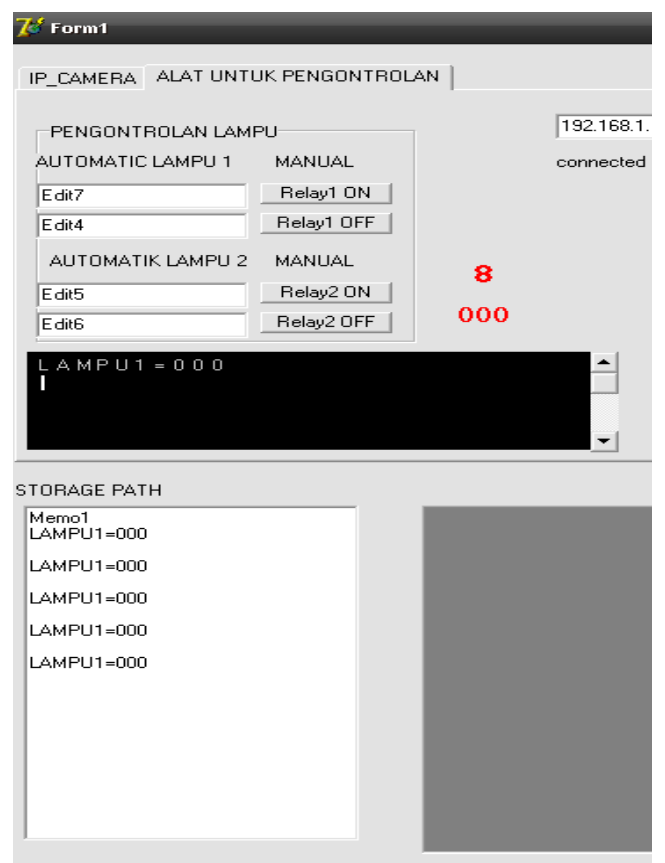

Gambar 7. Rangkaian Reciver 
Di Storage Path pada form diatas akan menunjukkan angka 000 yang mana angka ini seperti pada data mikrokontroller saat tanpa beban.

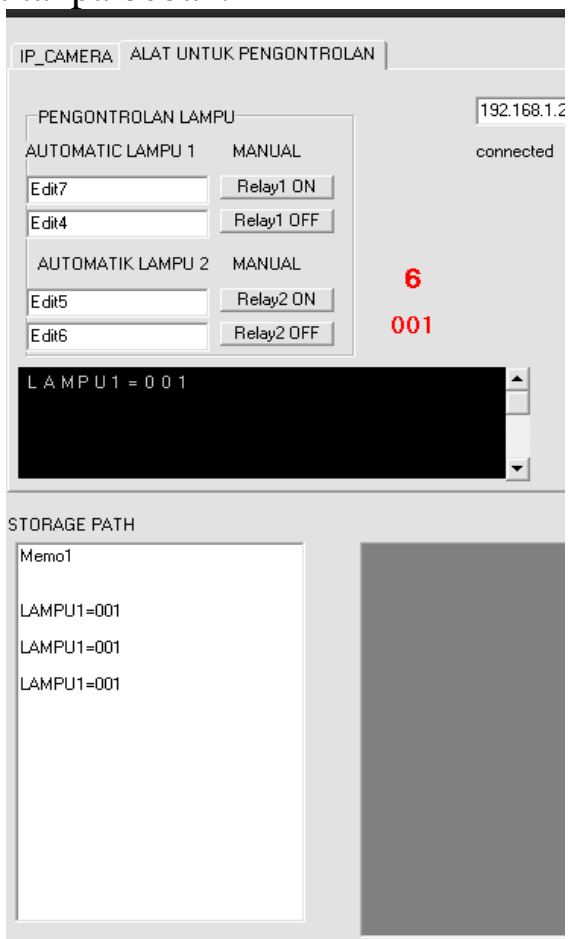

Gambar 8. Pengecekan Pengiriman Data Pada Delphi Dengan Beban

\section{Analisis Pengukuran Pada Alat}

Alat tersebut diperlukan untuk mengetahui alat ini bekerja atau tidak. Salah satu contoh pengukuran adalah mengukur tegangan output yang akan masuk ke mikrokontroller.

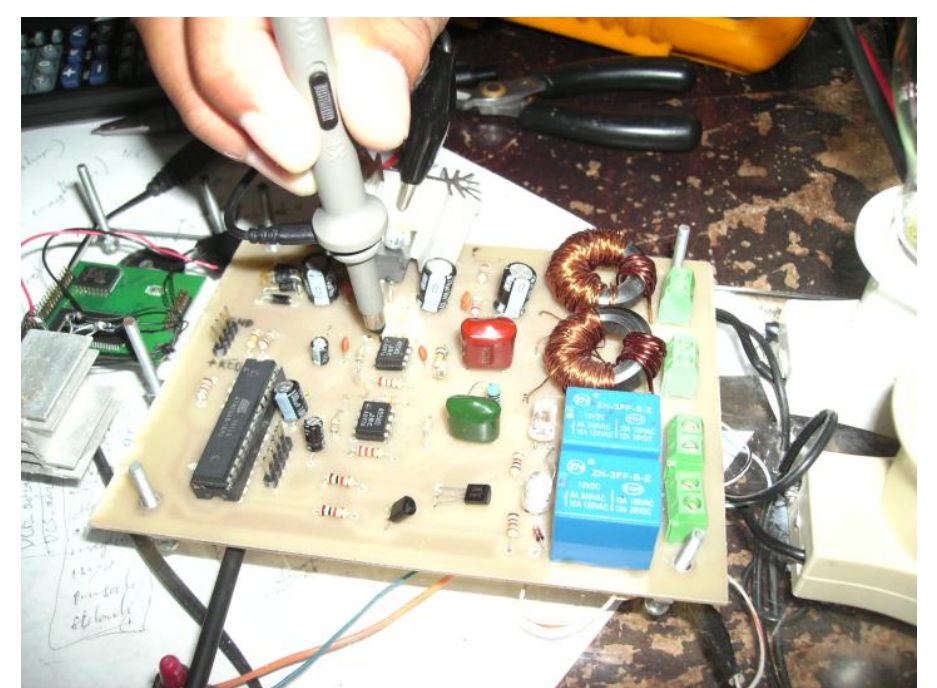

Gambar 9. Pengukuran Tegangan yang Masuk Pada Mikrokontroller

Yang mana mikrokontroller dapat membaca atau tidak tegangan yang diterima, dan pada percobaan tersebut digunakan lampu pijar 3 buah, yang memiliki masing-masing daya yang berbeda. Yaitu 40 Watt, 75 Watt dan 100 Watt. 
Tabel 1. Pengukuran Data

\begin{tabular}{|c|c|c|c|c|}
\hline NO. & $\begin{array}{l}\text { DAYA } \\
\text { LAMPU }\end{array}$ & $\begin{array}{l}\text { DATA YANG TERBACA } \\
\text { PADA } \\
\text { MIKROKONTROLLER }\end{array}$ & ARUS & $\begin{array}{lr}\text { TEGANGAN } & \text { YANG } \\
\text { MASUK } & \text { PADA } \\
\text { MIKROKONTROLLER }\end{array}$ \\
\hline 1. & 40 WATT & $\mathrm{OE}$ & $0,14 \mathrm{~A}$ & $0,16 \mathrm{~V}$ \\
\hline 2. & 75 WATT & $2 \mathrm{~A}$ & $0,27 \mathrm{~A}$ & $0,8 \mathrm{~V}$ \\
\hline 3. & $100 \mathrm{WATT}$ & $2 \mathrm{C}$ & $0,39 \mathrm{~A}$ & $0,87 \mathrm{~V}$ \\
\hline
\end{tabular}

\section{KESIMPULAN}

Dari pembahasan rancangan yang telah diuji maka dapat diambil suatu kesimpulan sebagai berikut :

1. Sistem pengontrolan jarak jauh AC dan lampu pada kelas di Politeknik Penerbangan Surabaya adalah merupakan sebuah perubahan dari sistem sebelumnya yaitu secara tradisional.

2. Sistem pengontrolan jarak jauh $\mathrm{AC}$ dan lampu sangat efektif untuk penghematan energi yang mana energi takkan terbuang percuma pada beban yang besar. Karena sistem ini juga dilengkapi dengan sistem sleep (waktu untuk hidup dan mati secara otomatis dapat kita atur).

\section{DAFTAR PUSTAKA}

Albert Gifson, S. (2009). SISTEM PEMANTAU RUANG JARAK JAUH DENGAN SENSOR PASSIVE INFRARED BERBASIS MIKROKONTROLER AT89S52. TELKOMNIKA, 201-206.

Helmi Guntoro, Y. S. (2013). RANCANG BANGUN MAGNETIC DOOR LOCK MENGGUNAKAN KEYPAD DAN SOLENOID BERBASIS MIKROKONTROLER ARDUINO UNO. ELECTRANS, 39-48.

Kiki Prawiroredjo, N. A. (2008). DETEKTOR JARAK DENGAN SENSOR ULTRASONIK BERBASIS MIKROKONTROLER. JETri, 41-52.

Mirza Gofur Saleh, S. (2013). PERANCANGAN DAN PEMBUATAN PROTOTYPE KODE PANGAMAN BERBASIS MIKROKONTROLER UNTUK SEPEDA MOTOR. INDEPT, 38-43.

Riny Sulistyowati, D. D. (2013). PERANCANGAN PROTOTYPE SISTEM KONTROL DAN MONITORING PEMBATAS DAYA LISTRIK BERBASIS MIKROKONTROLER. Jurnal IPTEK, 24-32.

Slamet Riyadi, B. E. (2013). SISTEM PENGENDALIAN KEAMANAN PINTU RUMAH BERBASIS SMS (SHORT MESSAGE SERVICE) MENGGUNAKAN MIKROKONTROLER ATMEGA 8535. Indonesian Journal on Networking and Security, 7-11. 